\title{
TRPV1 activation induces cell death of TM3 mouse Leydig cells
}

\author{
Eun-Jin Kim $^{1, \#}$, Long Cao Dang, ${ }^{1,2,}$, Marie Merci Nyiramana ${ }^{1,2}$, Adrian S. Siregar ${ }^{1,2}$, Min-Seok Woo ${ }^{1}$, \\ Chang-Woon $\mathrm{Kim}^{3}$ and Dawon Kang ${ }^{1,2, *}$
}

${ }^{1}$ Department of Physiology, College of Medicine and Institute of Health Sciences, Gyeongsang National University, Jinju 52727, Korea

${ }^{2}$ Department of Convergence Medical Science, Gyeongsang National University, Jinju 52727, Korea

${ }^{3}$ Department of Obstetrics and Gynecology, Samsung Changwon Hospital, Sungkyunkwan University School of

Medicine, Changwon 51353, Korea

Received September 17, 2021

Revised September 19, 2021

Accepted September 22, 2021

\section{*Correspondence}

Dawon Kang

E-mail: dawon@gnu.ac.kr

ORCID

https://orcid.org/0000-0001-7402-7298

"These authors contributed equally to this work.

\begin{abstract}
The role of transient receptor potential vanilloid receptor-1 (TRPV1) has been primarily investigated in pain sensory neurons. Relatively, little research has been performed in testicular cells. TRPV1 is abundantly expressed in Leydig cells of young adult mice. This study was conducted to determine the role of the TRPV1 channel in Leydig cells. TRPV1 modulators and testosterone were treated to the mouse Leydig cell line TM3 cells for $24 \mathrm{~h}$. Capsaicin, a TRPV1 activator, dose-dependently induced cell death, whereas capsazepine, a TRPV1 inhibitor, inhibited capsaicin-induced cell death. Testosterone treatment reduced capsaicin-induced cell death. High concentrations of testosterone decreased TRPV1 mRNA and protein expression levels. However, TRPV1 modulators did not affect testosterone production. These results showed that capsaicin induced cell death of Leydig cells and that testosterone reduced capsaicininduced cell death. Our findings suggest that testosterone may regulate the survival of Leydig cells in young adult mice by decreasing the expression level of TRPV1.
\end{abstract}

Keywords: apoptosis, Leydig cells, mice, testes, TRPV1

\section{INTRODUCTION}

Transient receptor potential vanilloid receptor-1 (TRPV1) is a nonselective cation channel that serves as a multimodal detector of noxious heat and proton stimuli (Caterina et al., 1997). The role of TRPV1 activated by noxious stimuli has been elucidated not only in pain sensory neurons but also in non-excitable cells. Compared to other ion channels, selective modulators of TRPV1 are well-known. The TRPV1 channel is activated by capsaicin and inhibited by capsazepine (Szallasi et al., 2007). Studies on the development of TRPV1 modulators other than capsaicin and cap- sazepine are ongoing. Cholesterol, a precursor to steroids, has been shown to influence the function of the TRPV1 channel directly in recent research (Méndez-Reséndiz et al., 2020). TRPV1 expression is increased by estrogens, whereas its protein level is decreased by progesterone. Androstenedione activates TRPV1, dehydroepiandrosterone (DHEA) inhibits TRPV1 activation, and testosterone is less effective at inhibiting TRPV1 activation. These findings suggest that these steroids directly affect regulation of TRPV1 channels (Méndez-Reséndiz et al., 2020). The role of steroids in the regulation of TRPV1 is still unclear.

TRPV1 activation in male germ cells is linked to cell 
survival or death (Mizrak et al., 2008; Mizrak and van Dissel-Emiliani, 2008; De Toni et al., 2016), as heat shock proteins control cell viability under various stress conditions (Santiago et al., 2019; Williams et al., 2019). The role of TRPV1 in testicular apoptosis remains controversial. The TRPV1 channel is known to be involved in tissue protection against oxidative damage with $17 \beta$-estradiol (Ramírez-Barrantes et al., 2020). TRPV1 KO mice have a testis phenotype with more cell death induced by oxidative stress stimuli and massive loss of germ cells from seminiferous tubules than wild-type (WT) mice (Mizrak and van Dissel-Emiliani, 2008; Martins et al., 2014). However, another report showed that TRPV1 KO mice have an extended lifespan and maintained youthfulness compared to WT at the same age (Riera et al., 2014). Our recent study showed that TRPV1 could induce testicular apoptosis (Siregar et al., 2019). The TRPV1 expression levels are significantly higher in the testes of older mice, with a distinct age-dependent expression pattern: a predominant expression in the Leydig cells of young adult mice and a similar level of expression throughout the testes of older mice (Siregar et al., 2019). TRPV1's function in Leydig cells is mostly unknown.

Leydig cells are interstitial cells in the testes that are located next to the seminiferous tubules. The most wellknown function of Leydig cells is to produce testosterone under the pulsatile control of pituitary luteinizing hormone (LH), which is required for the testes to maintain spermatogenesis (Smith and Walker, 2014). A recent study demonstrated that capsaicin induces apoptosis in CCL-97 Leydig cells, whereas capsazepine suppresses apoptosis, indicating that the TRPV1 channel is involved in Leydig cell apoptosis (Defo Deeh et al., 2019). Testosterone affects TRPV1 expression levels in a rat chronic inflammatory pain model (Bai et al., 2018) and inhibits TRPV1mediated currents (Ramírez-Barrantes et al., 2020). Little is known about the relationship between TRPV1 activity and testosterone secretion.

This study was performed to determine the relationship between TRPV1 expression, testosterone secretion, and apoptosis in the mouse Leydig cell line TM3 cells treated with TRPV1 modulators or manipulated TRPV1 expression.

\section{MATERIALS AND METHODS}

\section{Chemicals}

All components of the medium and other chemicals were tissue culture grade and were purchased from Sigma Chemical Co. (MO, USA), unless otherwise noted. Capsaicin (50 mM), capsazepine (10 mM), and testosterone (17 $\mathrm{mM}$ ) were dissolved in ethanol, methanol, and methanol, respectively, to produce the stock solution. All chemicals were diluted in the culture medium to their working concentration.

\section{Animals and testis isolation}

Male mice (C57BL/6J, six weeks old) were obtained from Central Lab. Animal Inc. (Seoul, Korea). The mice were housed in a pathogen-free area for 1 week under a $12 \mathrm{~h}$ light/dark cycle, with free access to food and water. Testes were isolated from mice at 7 weeks of age. Animal experiments were performed according to the guidelines of the Gyeongsang National University Animal Care and Use Committee (GNU-161219-M0072).

\section{Cell culture}

Mouse Leydig cell line TM3 (American Type Culture Collection, MD, USA) was kindly gifted by Dr. Jung Hye Shin (Namhae Garlic Research Institute, Namhae, Korea). Cell culture was carried out as described previously (Yang et al., 2019). The cells were cultured in Dulbecco's modified Eagle's medium (DMEM; Gibco/Life technologies, NY, USA) supplemented with $10 \%$ fetal bovine serum (FBS; Gibco), $100 \mathrm{U} / \mathrm{mL}$ penicillin (Gibco), and $100 \mathrm{mg} / \mathrm{mL}$ streptomycin (Gibco). The cells were incubated at $37^{\circ} \mathrm{C}$ in a $95 \%$ air and $5 \% \mathrm{CO}_{2}$ gas mixture, and the medium was replaced every other day.

\section{Cell viability assay}

The cell viability of TM3 treated with capsaicin, capsazepine, and testosterone was determined using a 3-(4,5-dimethylthiazole-2-yl)-2,5-diphenyl tetrazolium bromide (MTT) reagent $(5 \mathrm{mg} / \mathrm{mL}$ in phosphate buffered saline (PBS), Duchefa Biochemie, Haarlem, Netherlands). The MTT assay was carried out as described previously (Yang et al., 2019). TM3 cells were seeded at $5 \times 10^{3}$ cells/well $(100 \mu \mathrm{L})$ in $96-$ well plates, and the cells were cultured for $24 \mathrm{~h}$ before treatment with chemicals. Chemicals were treated for $24 \mathrm{~h}$. MTT solution $(10 \mu \mathrm{L}$ of $5 \mathrm{mg} / \mathrm{mL}$, Duch- 
efa Biochemie) was added to each well and incubated for $2 \mathrm{~h}$ at $37^{\circ} \mathrm{C}$ in the dark. The supernatants were aspirated and then the formazan crystals in each well were dissolved in $100 \mu \mathrm{L}$ DMSO for $10 \mathrm{~min}$ at room temperature by shaking. The absorbance was measured at $570 \mathrm{~nm}$ using a VERSAmax ${ }^{\mathrm{TM}}$ microplate reader (Molecular Devices, CA, USA).

\section{Transfection}

Transfection was performed with Magnetofection ${ }^{\mathrm{TM}}$ reagent according to the manufacturer's protocol (chemicell $\mathrm{GmbH}$, Berlin, Germany). The transfection was carried out as described previously (Yang et al., 2019). Briefly, HEK-293 and TM3 cells were cultured 24 h prior to transfection at a density of $2 \times 10^{5}$ cells per $60 \mathrm{~mm}$ dish in DMEM containing 10\% FBS. TM3 cells were transfected with DNA fragments encoding rat TRPV1 (NM_031982.1) in pcDNA3.1 or TRPV1 small interfering RNA (siRNA) using Magnetofection reagents (chemicell $\mathrm{GmbH}$ ) and OptiMEM I Reduced Serum Medium (Opti-MEM, Gibco). For gene silencing with small interfering RNA (siRNA), TM3 cells were transfected with $75 \mathrm{nM}$ of scrambled siRNA (negative control, ON-TARGET Non-Targeting Pool; Dharmacon, Lafayette, CO, USA) or TRPV1 ON-TARGETplus SMARTpool siRNA (Dharmacon) in serum-free medium using DharmaFECT transfection reagent (Dharmacon). After incubation for $6 \mathrm{~h}$, cells were changed with fresh medium and grown for an additional day. The effects of gene silencing were determined by reverse transcriptase polymerase chain reaction (RT-PCR) and Western blot analyses.

\section{Annexin V/propidium iodide ( $\mathrm{PI})$ staining}

Apoptotic signals were detected using the FITC Annexin $\mathrm{V}$ apoptosis detection kit (BD Biosciences, NJ, USA) according to the manufacturer's protocol. The transfection was carried out as described previously (Nyiramana et al., 2020). Briefly, cells grown on a glass-bottomed culture dish (SPL) were labeled with FITC Annexin V labeling reagent and PI (BD Biosciences), and then incubated for 15 min at room temperature in the dark. Following incubation, the cells were analyzed using a confocal laser scanning microscope (Olympus, Tokyo, Japan).

\section{Hematoxylin and eosin (H\&E) staining}

Histological alterations in testes were analyzed by stain- ing with hematoxylin and eosin (H\&E) solution. The H\&E staining was carried out as described previously (Siregar et al., 2019). The tissues were fixed overnight at $4{ }^{\circ} \mathrm{C}$ in $4 \%$ paraformaldehyde solution, rinsed in $0.1 \mathrm{M}$ PBS, embedded in paraffin, and cut into $5 \mu \mathrm{m}$-thick slices. The paraffin slices were air-dried on gelatin-coated slides, deparaffinized, and then cleaned with tap water for $5 \mathrm{~min}$. The tissue sections were then submerged in hematoxylin solution for $5 \mathrm{~min}$ after being washed. The degree of hematoxylin staining was checked in tap water, followed by eosin staining for $1 \mathrm{~min}$. The sections were dehydrated in a series of alcohols ( $70 \%$ to $100 \%$ ethanol, 3 min each), cleared in xylene, and mounted with permount mounting medium (Fisher Chemical, Geel, Belgium). The stained tissue sections were observed and photographed using a BX61VS microscope (Olympus, Tokyo, Japan). Five sections from each sample were evaluated.

\section{Immunohistochemistry (IHC)}

To identify the expression and localization of TRPV1, the testis sections were processed by immunohistochemistry. The IHC was carried out as described previously (Siregar et al., 2019). Deparaffinized tissue sections were permeabilized with $0.2 \%$ Triton $\mathrm{X}-100$ for $10 \mathrm{~min}$ at room temperature. After three washes in PBS, the sections were incubated with blocking buffer (10\% normal goat serum in $0.1 \mathrm{M} \mathrm{PBS}$ ) for $60 \mathrm{~min}$ at room temperature. Without washing, the sections were then incubated with rabbit polyclonal anti-TRPV1 (1:200 dilutions, Alomone Lab, Jerusalem, Israel) primary antibody overnight at $4^{\circ} \mathrm{C}$. After three washes in PBS, the sections were incubated in the dark for 1.5 h with FITC-conjugated anti-rabbit IgG secondary antibody (Abcam, Cambridge, UK) diluted at 1:400 in PBS. Finally, the sections were washed three times in PBS and stained with propidium iodide (PI) for nuclei staining. The stained sections were wet-mounted with Gel/Mount ${ }^{\mathrm{TM}}$ (Biomeda Corp., CA, USA) and observed using a confocal laser scanning microscope (Olympus).

\section{TUNEL staining}

The apoptotic signal in the testes was assessed using the DeadEnd ${ }^{\mathrm{TM}}$ Fluorometric TUNEL System (Promega, Madison, WI, USA) according to the manufacturer's protocol. The TUNEL staining was carried out as described previously (Siregar et al., 2019). Deparaffinized tissue sections were fixed in $4 \%$ paraformaldehyde in PBS for 
$15 \mathrm{~min}$ at room temperature, washed three times in PBS, and permeabilized with $20 \mu \mathrm{g} / \mathrm{mL}$ proteinase $\mathrm{K}$ solution for $10 \mathrm{~min}$ at room temperature. After three washes in PBS, the slides were refixed in $4 \%$ paraformaldehyde for 5 min at room temperature. The slides were washed in PBS for $5 \mathrm{~min}$ and equilibrated in an equilibration buffer for $10 \mathrm{~min}$. The tissues were labeled with $\mathrm{TdT}$ reaction mix for $60 \mathrm{~min}$ at $37^{\circ} \mathrm{C}$ in a dark humidified chamber. The reaction was stopped with $2 \mathrm{X}$ SSC solution, followed by washing three time in PBS. Counter staining was carried out by incubating with $5 \mu \mathrm{g} / \mathrm{mL}$ PI for $10 \mathrm{~min}$ at room temperature in the dark. TUNEL-positive cells were observed using a confocal laser scanning microscope (Olympus).

\section{Isolation of total RNA and reverse transcriptase- polymerase chain reaction (RT-PCR)}

Total RNA was isolated from TM3 cells using TRIzolTM Reagent (Invitrogen, CA, USA) according to the manufacturer's instructions. The total RNA isolation and RT-PCR were carried out as described previously (Siregar et al., 2019). Briefly, after washing the cells three times with $1 \mathrm{X}$ PBS, the Trizol ${ }^{\mathrm{TM}}$ Reagent was added directly to the cells in the culture dish. The cells were scrapped and lysed by pipetting up and down several times. The cell homogenate were transferred to an Eppendorf tube and incubated for $5 \mathrm{~min}$ at room temperature to permit the complete dissociation of the nucleoprotein complex. Chloroform was added to a volume of $20 \%$ of TRIzol's volume and shaken vigorously for $15 \mathrm{sec}$. The mixture was incubated for $3 \mathrm{~min}$ at room temperature before centrifugation for $10 \mathrm{~min}$ at $12,000 \times \mathrm{g}$ at $4^{\circ} \mathrm{C}$. The aqueous samples were transferred to a new Eppendorf tube, precipitated by adding $100 \%$ isopropanol, and incubated for $10 \mathrm{~min}$ at room temperature prior to the centrifugation at $12,000 \times \mathrm{g}$ for 10 min at $4^{\circ} \mathrm{C}$. The RNA pellets were washed with $75 \%$ ethanol, and then the sample was vortexed briefly, centrifuged at 7,500 $\times \mathrm{g}$ for $5 \mathrm{~min}$ at $4^{\circ} \mathrm{C}$, air-dried for $10 \mathrm{~min}$, and resuspended in diethylpyrocarbonate (DEPC)-treated RNase-free water.

The isolated total RNA (3 $\mu \mathrm{g})$ was used to synthesize the first-strand cDNA using a reverse transcriptase kit (DiaStartTM RT kit; SolGent, Daejeon, Korea). PCR amplification was performed by using first-strand cDNA, Taq polymerase (G-Taq, Cosmo Genetech, Seoul, Korea), and specific primers for mouse TRPV1 (\#NM_001001445.2, forward: 5'- GCATCTTCTACTTCAACTTCTTCG -3' and reverse: 5'-CCACATACTCCTTGCGATGG-3'). Glyceraldehydes-3-phosphate dehydrogenase (GAPDH, \#NM_017008, forward: 5'-CTAAAGGGCATCCTGGGC-3' and reverse: 5'-TTACTCCTTGGAGGCCATG-3') was used as a loading control. The PCR conditions included initial denaturation at $94^{\circ} \mathrm{C}$ for $5 \mathrm{~min}$, then 35 cycles at $94^{\circ} \mathrm{C}$ for $30 \mathrm{~s}, 60^{\circ} \mathrm{C}$ for $30 \mathrm{~s}$, and $72^{\circ} \mathrm{C}$ for $30 \mathrm{~s}$, and a final extension step at $72^{\circ} \mathrm{C}$ for $10 \mathrm{~min}$. The PCR products were electrophoresed on a $1.5 \%(\mathrm{w} / \mathrm{v})$ agarose gel to verify the product size. The images of DNA fragments were directly captured and visualized with the iBright ${ }^{\mathrm{TM}}$ CL1500 imaging system (Thermo Scientific Fisher/Life Technologies Holdings Pte Ltd., Singapore). The DNA fragments were directly sequenced with the ABI PRISM ${ }^{\circledR}$ 3100-Avant Genetic Analyzer (Applied Biosystems, CA, USA).

\section{Western blot analysis}

Western blot analysis was carried out as described previously (Yang et al., 2019). TM3 cells $\left(5 \times 10^{4}\right.$ cells $/ 60 \mathrm{~mm}$ dish) were treated with a various concentration of testosterone for $24 \mathrm{~h}$. Total protein was isolated from TM3 cells using the RIPA buffer (Thermo Fisher Scientific., MA, USA) containing a $1 \times$ protease inhibitor cocktail (Roche Diagnostics., IN, USA). The cell lysates were incubated for $30 \mathrm{~min}$ on ice with intermittent vortexing and were clarified by centrifugation at 15,871 $\times \mathrm{g}(13,000 \mathrm{rpm}$, Eppendorf, Hamburg, Germany) at $4^{\circ} \mathrm{C}$ for $20 \mathrm{~min}$. Protein concentration in cell lysates was quantified using a Pierce bicinchoninic acid (BCA) protein assay kit (Thermo Fisher Scientific). Equal amounts of proteins mixed with $1 \times$ loading buffer were separated on $8 \%$ sodium dodecyl sulfate (SDS)-polyacrylamide gel by electrophoresis for 2 $\mathrm{h}$ at $100 \mathrm{~V}$, and the gel was blotted onto a polyvinylidene difluoride (PVDF, Millipore, MA, USA) membrane for 70 min at $100 \mathrm{~V}$ using a tank transfer method. Membranes were blocked with $5 \%(\mathrm{w} / \mathrm{v})$ fat-free dry milk in tris buffered saline with Tween20 (TBST; $20 \mathrm{mM}$ Tris $\mathrm{HCl}(\mathrm{pH} 8)$, $150 \mathrm{mM} \mathrm{NaCl}$, and $0.1 \%$ Tween-20) at room temperature for $120 \mathrm{~min}$ and then incubated with polyclonal antiTRPV1 antibody (1:1000 dilution, Alomone Labs), monoclonal or anti- $\beta$-actin antibody (1:5000 dilution) at $4{ }^{\circ} \mathrm{C}$ overnight. The primary antibody incubation was followed by incubation with a secondary horseradish peroxidase (HRP)-conjugated anti-rabbit or anti-mouse antibody at 1:10000 (Assay Designs, Ann Arbor, MI, USA). Immuno- 
positive bands were developed by an enhanced chemiluminescence (Thermo Fisher Scientific), and visualized with the iBright $^{\mathrm{TM}}$ CL1500 imaging system (Thermo Scientific Fisher/Life Technologies Holdings Pte Ltd.). The relative protein level was calculated using $\beta$-actin as a loading control.

\section{Measurement of testosterone concentration}

Testosterone concentration was measured in supernatants obtained from TM3 cells treated with capsaicin and capsazepine using the mouse testosterone ELISA kit (CUSABIO, TX, USA) according to the manufacturer's instructions. Briefly, standards or samples $(50 \mu \mathrm{L})$, HRPconjugate $(50 \mu \mathrm{L})$, and antibody $(50 \mu \mathrm{L})$ were added to each well, mixed well, and incubated for $1 \mathrm{~h}$ at $37^{\circ} \mathrm{C}$. The liquid was aspirated and washed three times with 1 $\times$ wash buffer after incubation. Then, substrate A $(50 \mu \mathrm{L})$ and substrate $\mathrm{B}(50 \mu \mathrm{L})$ were added, thoroughly mixed, and incubated for $15 \mathrm{~min}$ at $37^{\circ} \mathrm{C}$. Finally, $50 \mu \mathrm{L}$ of stop solution was added to each well, and the plate was tapped to ensure thorough mixing. Using a microplate reader set to $450 \mathrm{~nm}$ (VERSAmax ${ }^{\mathrm{TM}}$ microplate reader), the optical density of each well was calculated in less than 10 min.

\section{Statistical analysis}

The data are represented as the mean \pm S.D. Significant differences between groups were evaluated using a oneway ANOVA/Bonferroni test (OriginPro2020, OriginLab Corp., MA, USA). A value of $p<0.05$ was considered to be significant.

\section{RESULTS}

\section{Expression of TRPV1 in Leydig cells in testis of young mice}

Mouse testes were used for H\&E and immunostainings. In young adult mice, $\mathrm{H} \& \mathrm{E}$ staining showed a normal histological appearance of seminiferous tubules. Spermatogenic cells, Sertoli cells, and Leydig cells were seen, and there was no pathological damage to the seminiferous tubules (Fig. 1A, $\mathrm{n}=3$ ). Immunohistochemical data showed that TRPV1 was predominantly expressed in Leydig cells distributed in seminiferous tubules (Fig. 1B, $n=3$ ). Apoptotic cells were not detected in testes of young mice, whereas apoptotic cells were seen in the DNase-treated positive control (PC) (Fig. 1C, $n=3$ ). As shown in Fig. 1C, green signals indicate TUNEL-labeled apoptotic cells, red signals indicate propidium iodide (PI) stained nucleus, and yellow signals indicate cells merged with TUNELpositive and PI-positive signals.

\section{Capsaicin-induced cell death}

The effect of TRPV1 modulators on TM3 cell viability was analyzed by an MTT assay. TM3 cells were treated with various concentrations of capsaicin $(1$ to $100 \mu \mathrm{M})$ and capsazepine (1 to $100 \mu \mathrm{M})$. Capsaicin induced cell death in a dose-dependent manner (Fig. $2 \mathrm{~A}, \mathrm{n}=6$ ), while capsazepine did not induce cell death (Fig. 2B, $n=6$ ). TRPV1 overexpressed cells showed significantly lower cell viability compared to vector transfected cells (Fig. $2 \mathrm{C}, \mathrm{p}<0.05, \mathrm{n}=3)$. Capsaicin $(30 \mu \mathrm{M})$-treated cells were double-positive for Annexin V-FITC (green) and PI (red), and the cytotoxicity of capsaicin was higher in TRPV1overexpressed TM3 cells than in vector-transfected cells (Fig. 2D, $\mathrm{n}=3$ ). Testosterone treatment did not induce cell death (Fig. 2E, $\mathrm{n}=6$ ). However, capsaicin-induced cell death was inhibited in the presence of $100 \mathrm{nM}$ testosterone (Fig. $2 \mathrm{~F}, \mathrm{n}=6)$. Capsaicin $(30 \mu \mathrm{M})$ and capsazepine $(30 \mu \mathrm{M})$ treatments did not induce testosterone production (Fig. $2 \mathrm{G}, \mathrm{n}=3$ ).
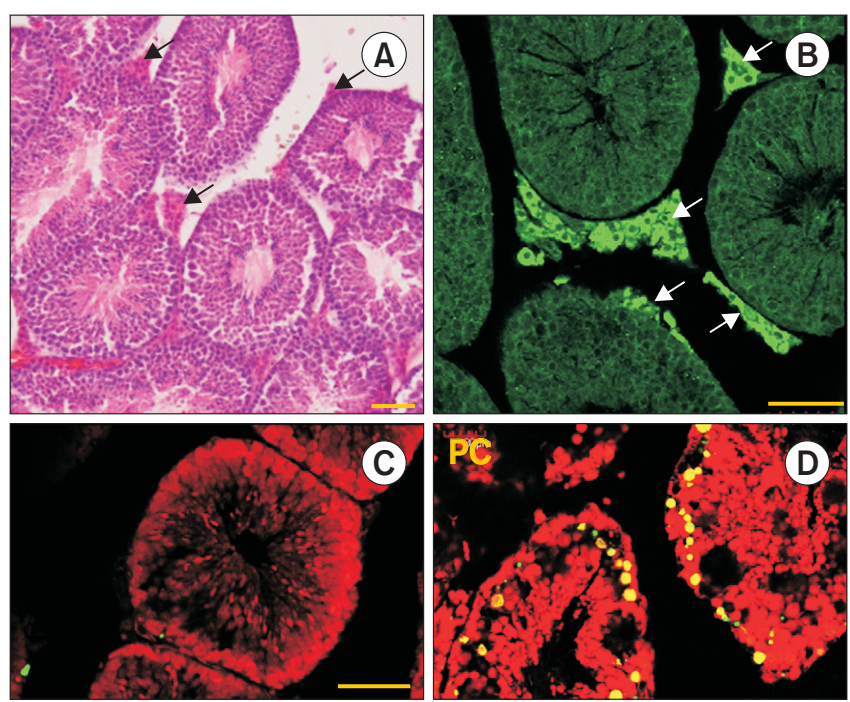

Fig. 1. Expression of TRPV1 in Leydig cells of young adult mice. (A) Microphotographs of testis sections. Histological image was obtained by H\&E staining. Arrows indicate Leydig cells. (B) TRPV1 immunostaining in testes. Strong green fluorescence intensity shows TRPV1 expression in Leydig cells. White arrows indicate TRPV1 expression in Leydig cells. (C) TUNEL staining. The green signals of TUNEL-labeled apoptotic cells and propidium iodide (PI) stained red signal were merged. The right panel shows the DNase I-treated positive control (PC). Each scale bar represents $50 \mu \mathrm{m}$. 

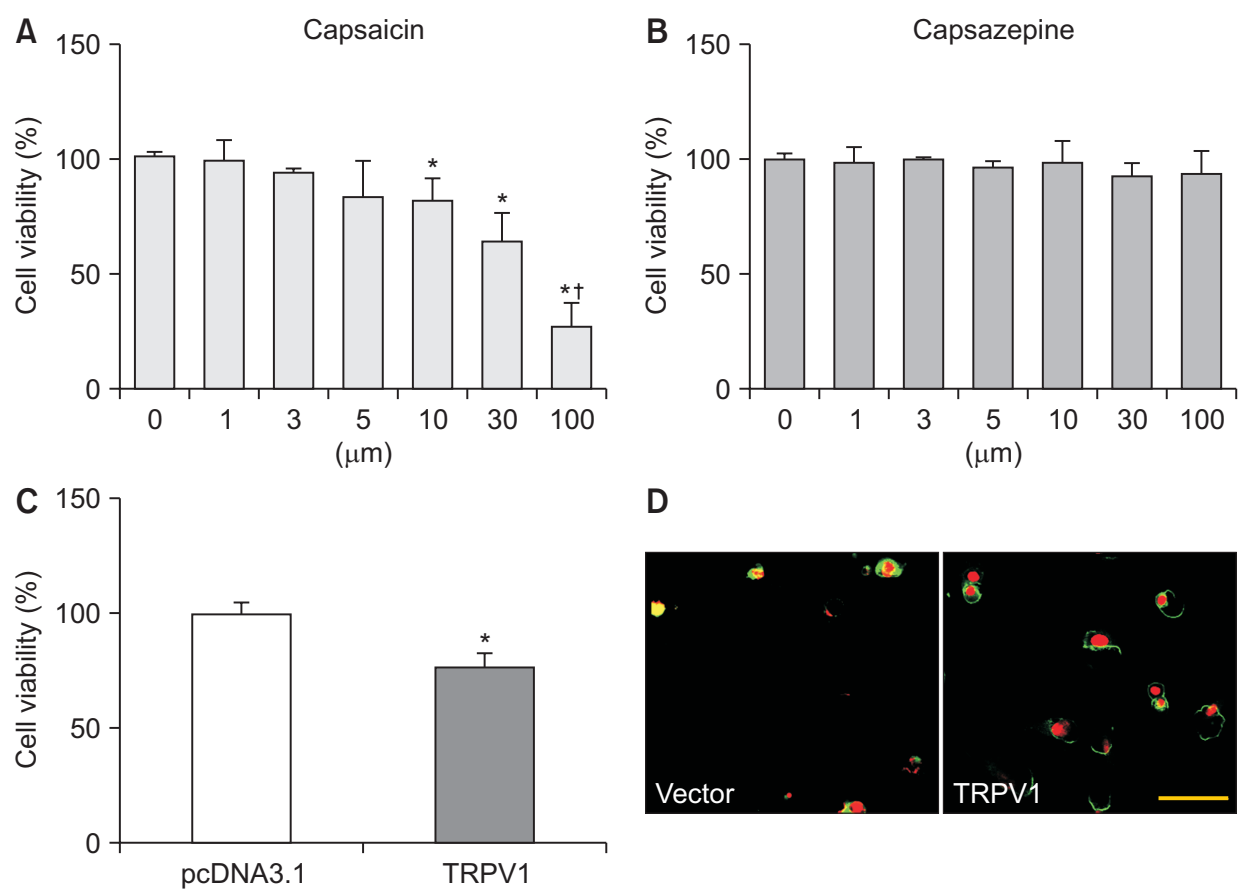

D
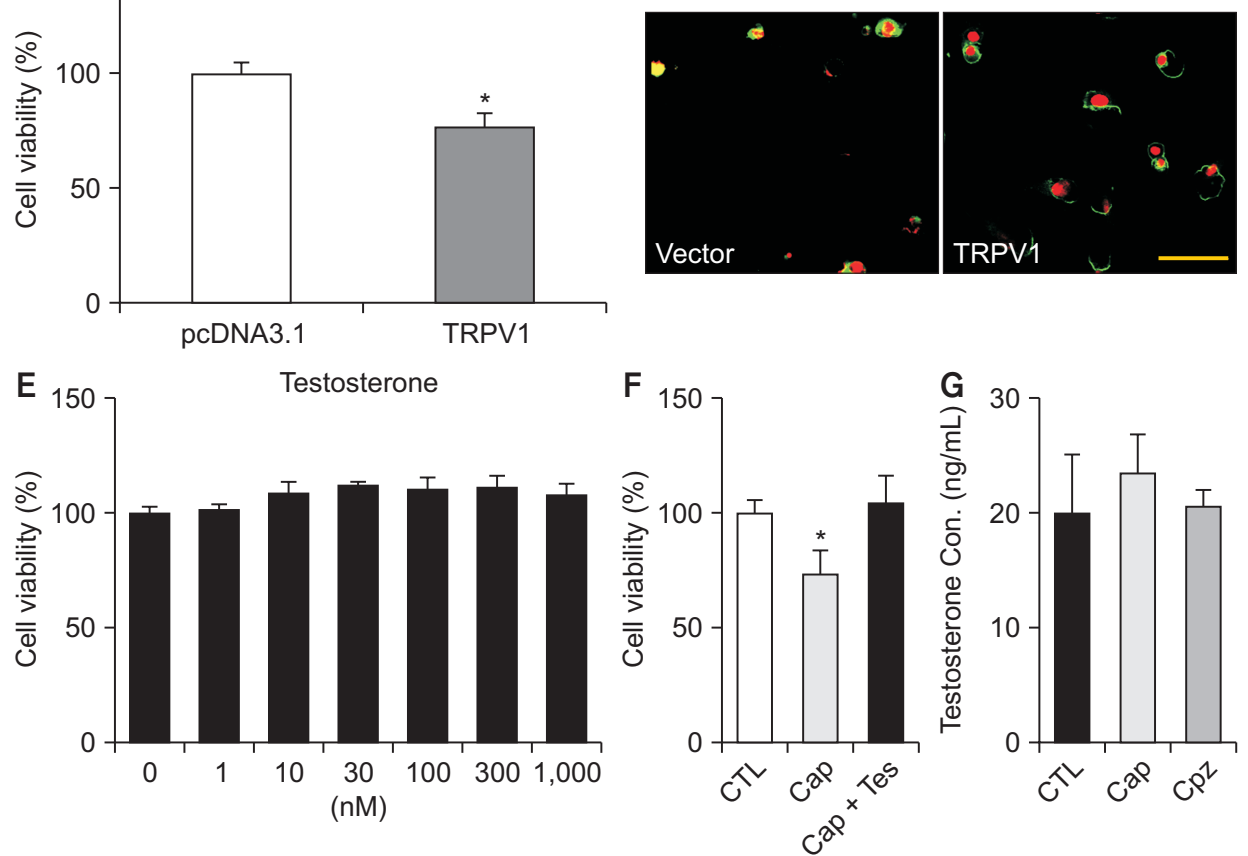

Fig. 2. TRPV1 activation-induced cell death in TM3 cells. (A and C) Cell viability. (A) Capsaicin effect. The cells were treated with various concentrations of capsaicin for $24 \mathrm{~h}$. (B) Capsazepine effect. (C) Effect of TRPV1 overexpression. (D) Annexin V/PI staining. Capsaicin was treated to vector or TRPV1 transfected cells for $24 \mathrm{~h}$. Representative Annexin V (green)/PI (red) images. Scale bar, $50 \mu \mathrm{m}$. (E) Effect of testosterone on cell viability. (F) Protection of capsaicin (30 $\mu \mathrm{M})$-induced cell death by testosterone (100 nM) pretreatment. (G) Testosterone concentration. After $24 \mathrm{~h}$ of treatment with capsaicin and capsazepine in TM3 cells, the concentration of testosterone secreted from cells was measured. Each bar represents mean \pm SD of three independent experiments. ${ }^{*} p<0.05$ compared to the control (solvent treatment). ${ }^{\dagger} p<0.05$ compared to the $10 \mu \mathrm{M}$ capsaicin treatment. CTL, Cap, Cpz, and Tes indicate control, capsaicin, capsazepine, and testosterone, respectively.

\section{Testosterone-induced decrease in TRPV1 expression}

To identify whether testosterone affects TRPV1 expression levels in TM3 cells, TRPV1 mRNA and protein expression levels were measured in TM3 cells treated with various concentrations of testosterone. TRPV1 mRNA levels were significantly decreased in TM3 cells treated with various concentrations of testosterone in a dose-dependent manner. The inhibition of TRPV1 mRNA expression levels was the highest in $100 \mathrm{nM}$ testosterone treatment
(Fig. 3A, n = 3). TRPV1 mRNA was not detected in the presence of 300 and $1000 \mathrm{nM}$ testosterone, indicating that high testosterone concentrations markedly suppressed TRPV1 expression (data not shown). TRPV1 protein levels were also decreased by testosterone treatment. Among the $10,30,50,100,300$, and $1000 \mathrm{nM}$ testosterone concentrations treated in TM3 cells, 300 and $1000 \mathrm{nM}$ testosterone significantly reduced TRPV1 protein levels (Fig. 3B, $p<0.05, \mathrm{n}=3$ ). 

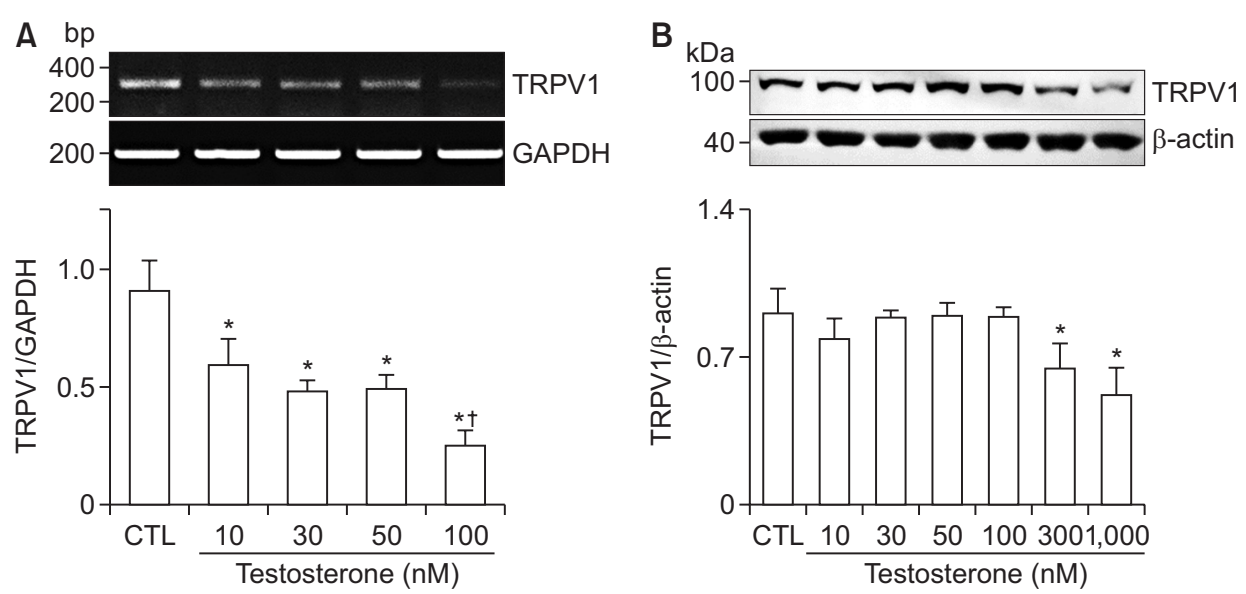

Fig. 3. Reduction of TRPV1 expression level by testosterone treatment in TM3 cells. (A) Changes in TRPV1 mRNA expression level by testosterone treatment. GAPDH was used as a loading control. (B) TRPV1 protein level changed by testosterone treatment. $\beta$-actin was used as a loading control. Each bar represents mean \pm SD of three independent experiments. ${ }^{*} p<0.05$ compared to the control (solvent treatment). ${ }^{\dagger} p<0.05$ compared to the $10 \mathrm{nM}$ testosterone.

\section{DISCUSSION}

TRPV1 has been mainly studied in sensory neurons. Relatively few studies have reported an association between TRPV1 and apoptosis in testicular cells. Our previous study reported that TRPV1 expressed highly in old mice was associated with testicular apoptosis. In young adult mice, TRPV1 was predominantly expressed in Leydig cells compared to other cells in testis (Siregar et al., 2019). High expression of TRPV1 in Leydig cells arouses our interest. Many questions have been raised based on the previous study. Does high expression of TRPV1 in Leydig cells protect against testicular apoptosis in young mice? Is there a relationship between testosterone secretion and the TRPV1 channel? Is testosterone linked to testicular apoptosis? Does testosterone affect TRPV1 expression levels? This study set out to answer these questions.

The testes of the male gonad contain Leydig cells, which are essential cells. Leydig cells are located between seminiferous tubules, which contain Sertoli cells and germ cells. These three cell types act together to sustain spermatogenesis and hormone regulation and are linked to pathological alterations (Al-Agha and Axiotis, 2007). This study focused only on Leydig cells and did not address the interactions of Leydig cells with Sertoli cells and germ cells. What role does TRPV1 strongly expressed in Leydig cells of young adult mice play? Under the hypothesis that it may be related to the secretion of testosterone, the main function of Leydig cells, testosterone secreted from
TM3 mouse Leydig cells treated with TRPV1 modulators was measured. Unfortunately, no significant difference between capsaicin and capsazepine treatments was found.

We answer questions about the relationship between testosterone, TRPV1, and apoptosis. Consistent with an earlier study (Defo Deeh et al., 2019), in the current study, TRPV1 activation increased Leydig cell death. Capsaicin treatment increased caspase 3 activity and ROS level as well as the depolarization of mitochondrial membrane potential (MMP) (Defo Deeh et al., 2019). High concentrations of testosterone decreased TRPV1 mRNA and protein expression levels in TM3 cells. In addition, capsaicininduced cell death was reduced in the presence of testosterone. Testosterone shows anti-apoptotic effects against hydrogen peroxide $\left(\mathrm{H}_{2} \mathrm{O}_{2}\right)$-induced apoptosis in C2C12 skeletal muscle cells (Pronsato et al., 2012). However, testosterone does not show any protection against hydrogen peroxide $\left(\mathrm{H}_{2} \mathrm{O}_{2}\right)$-induced cell death in Hela cells and hippocampal neurons (Ramírez-Barrantes et al., 2020). The testosterone effect is also complicated, and it differs in different cells due to various mechanisms of action, affecting cell viability in different ways.

These results suggest that testosterone may contribute to hormone secretion and spermatogenesis through suppressing testicular apoptosis by reducing the expression level of TRPV1 in young adult mice, which secrete relatively higher levels of testosterone than older mice. In general, the normal range for testosterone in men is 
approximately $270-1070 \mathrm{ng} / \mathrm{dL}$, with an average level of $670 \mathrm{ng} / \mathrm{dL}$. Normal male testosterone levels peak around age 20 and then slowly decline (https://www.medicinenet. com/high and low testosterone levels in men; accessed data Sep.12. 2021). The age of mice that can be compared to 'adult' in humans ranges from 6 to 20 weeks (Jackson et al., 2017). In this study, 7-week-old mice were used as adults.

However, there are still questions about the role of TRPV1 highly expressed in Leydig cells and its interaction with Sertoli cells and germ cells. TRPV1 is activated by estrogen, but inhibited by testosterone (Chen et al., 2004). Androgen receptors are expressed in the nucleus of Sertoli cells and in the cytoplasm of sperm. Estrogen receptors $\alpha$ and $\beta$ were observed only in the nucleus of Leydig cells of non-steroidal aromatase inhibitor-treated rats (Pilutin et al., 2014). The types of steroid hormone receptors expressed in each cell are different, and the response of TRPV1 to the hormone is different (Méndez-Reséndiz et al., 2020; Ramírez-Barrantes et al., 2020). An integrated study of Sertoli, germ, and Leydig cells is needed to further understand the role of TRPV1 in hormone secretion and spermatogenesis. In addition, further studies should examine changes in TRPV1 expression in response to testosterone concentrations in a mouse model to discuss the in vivo link and related signaling pathways.

\section{CONCLUSION}

In conclusion, TRPV1 activation induced cell death, and testosterone decreased the TRPV1 expression level in Leydig cells. Capsaicin-induced cell death was inhibited in the presence of testosterone. These results suggest that testosterone may be involved in regulating the survival of Leydig cells by decreasing the expression level of TRPV1.

\section{CONFLICTS OF INTEREST}

No potential conflict of interest relevant to this article was reported.

\section{ACKNOWLEDGEMENTS}

This work was supported by the Basic Science Research Program through the National Research Foundation of Korea funded by the Ministry of Education
(2021R1I1A3044128) and the Ministry of Science and ICT (2015R1A5A2008833).

\section{AUTHOR CONTRIBUTIONS}

\author{
Conceptualization: DK \\ Data curation: EJK, LCD, MMN, DK \\ Formal analysis: EJK, LCD, MMN, MSW, DK \\ Funding acquisition: DK \\ Investigation: EJK, LCD, MMN, CWK, DK \\ Methodology: EJK, LCD, MMN, MSW, DK \\ Project administration: EJK \\ Supervision: DK \\ Validation: DK \\ Visualization: EJK, LCD, MMN, DK \\ Writing - original draft: DK \\ Writing - review \& editing: DK
}

\section{AUTHOR'S POSITION AND ORCID NO.}

Kim EJ, Postdoctoral Researcher,

https://orcid.org/0000-0003-1068-9334

Cao Dang L, MS Student,

https://orcid.org/0000-0001-8203-4631

Nyiramana MM, Ph.D Student,

https://orcid.org/0000-0002-0018-8934

Siregar AS, Postdoctoral Researcher,

https://orcid.org/0000-0001-7069-4202

Woo MS, Postdoctoral Researcher,

https://orcid.org/0000-0002-0357-9666

Kim CW, Professor,

https://orcid.org/0000-0002-6663-0764

Kang D, Professor,

https://orcid.org/0000-0001-7402-7298

\section{REFERENCES}

Al-Agha OM and Axiotis CA. 2007. An in-depth look at Leydig cell tumor of the testis. Arch. Pathol. Lab. Med. 131:311-317.

Bai X, Zhang X, Zhou Q. 2018. Effect of testosterone on TRPV1 expression in a model of orofacial myositis pain in the rat. J. Mol. Neurosci. 64:93-101.

Caterina MJ, Schumacher MA, Tominaga M, Rosen TA, Levine JD, Julius D. 1997. The capsaicin receptor: a heat-activated ion channel in the pain pathway. Nature 389:816-824.

Chen SC, Chang TJ, Wu FS. 2004. Competitive inhibition of the capsaicin receptor-mediated current by dehydroepiandrosterone in rat dorsal root ganglion neurons. J. Pharmacol. 
Exp. Ther. 311:529-536.

Defo Deeh PB, Watcho P, Wankeu-Nya M, Ngadjui E, Usman UZ. 2019. The methanolic extract of Guibourtia tessmannii (caesalpiniaceae) and selenium modulate cytosolic calcium accumulation, apoptosis and oxidative stress in R2C tumour Leydig cells: involvement of TRPV1 channels. Andrologia 51:e13216.

De Toni L, Garolla A, Menegazzo M, Magagna S, Di Nisio A, Šabović I, Rocca MS, Scattolini V, Filippi A, Foresta C. 2016. Heat sensing receptor TRPV1 is a mediator of thermotaxis in human spermatozoa. PLoS One 11:e0167622.

Jackson SJ, Andrews N, Ball D, Bellantuono I, Gray J, Hachoumi L, Holmes A, Latcham J, Petrie A, Potter P, Rice A, Ritchie A, Stewart M, Strepka C, Yeoman M, Chapman K. 2017. Does age matter? The impact of rodent age on study outcomes. Lab. Anim. 51:160-169.

Martins D, Tavares I, Morgado C. 2014. "Hotheaded": the role OF TRPV1 in brain functions. Neuropharmacology 85:151157.

Mizrak SC, Gadella BM, Erdost H, Ozer A, van Pelt AM, van Dissel-Emiliani FM. 2008. Spermatogonial stem cell sensitivity to capsaicin: an in vitro study. Reprod. Biol. Endocrinol. 6:52.

Mizrak SC and van Dissel-Emiliani FM. 2008. Transient receptor potential vanilloid receptor-1 confers heat resistance to male germ cells. Fertil. Steril. 90:1290-1293.

Méndez-Reséndiz KA, Enciso-Pablo Ó, González-Ramírez R, Juárez-Contreras R, Rosenbaum T, Morales-Lázaro SL. 2020. Steroids and TRP channels: a close relationship. Int. J. Mol. Sci. 21:3819.

Nyiramana MM, Cho SB, Kim EJ, Kim MJ, Ryu JH, Nam HJ, Kim NG, Park SH, Choi YJ, Kang SS, Jung M, Shin MK, Han J, Jang IS, Kang D. 2020. Sea hare hydrolysate-induced reduction of human non-small cell lung cancer cell growth through regulation of macrophage polarization and non-apoptotic regulated cell death pathways. Cancers (Basel) 12:726.

Pilutin A, Misiakiewicz-Has K, Kolasa A, Baranowska-Bosiacka I, Marchlewicz M, Wiszniewska B. 2014. The immunoex- pression of androgen receptor, estrogen receptors alpha and beta, vanilloid type 1 receptor and cytochrome p450 aromatase in rats testis chronically treated with letrozole, an aromatase inhibitor. Folia Histochem Cytobiol 52:206-217.

Pronsato L, Boland R, Milanesi L. 2012. Testosterone exerts antiapoptotic effects against $\mathrm{H} 2 \mathrm{O} 2$ in $\mathrm{C} 2 \mathrm{C} 12$ skeletal muscle cells through the apoptotic intrinsic pathway. J. Endocrinol. 212:371-381.

Ramírez-Barrantes R, Carvajal-Zamorano K, Rodriguez B, Cordova C, Lozano C, Simon F, Díaz P, Muñoz P, Marchant I, Latorre R, Castillo K, Olivero P. 2020. TRPV1-estradiol stereospecific relationship underlies cell survival in oxidative cell death. Front. Physiol. 11:444.

Riera CE, Huising MO, Follett P, Leblanc M, Halloran J, Van Andel R, de Magalhaes Filho CD, Merkwirth C, Dillin A. 2014. TRPV1 pain receptors regulate longevity and metabolism by neuropeptide signaling. Cell 157:1023-1036.

Santiago J, Silva JV, Fardilha M. 2019. First insights on the presence of the unfolded protein response in human spermatozoa. Int. J. Mol. Sci. 20:5518.

Siregar AS, Nyiramana MM, Kim EJ, Shin EJ, Kim CW, Lee DK, Hong SG, Han J, Kang D. 2019. TRPV1 is associated with testicular apoptosis in mice. J. Anim. Reprod. Biotechnol. 34:311-317.

Smith LB and Walker WH. 2014. The regulation of spermatogenesis by androgens. Semin. Cell Dev. Biol. 30:2-13.

Szallasi A, Cortright DN, Blum CA, Eid SR. 2007. The vanilloid receptor TRPV1: 10 years from channel cloning to antagonist proof-of-concept. Nat. Rev. Drug Discov. 6:357-372.

Williams PA, Kobilnyk HE, McMillan EA, Strochlic TI. 2019. MAPKAP kinase 2-mediated phosphorylation of HspA1L protects male germ cells from heat stress-induced apoptosis. Cell Stress Chaperones 24:1127-1136.

Yang JH, Siregar AS, Kim EJ, Nyiramana MM, Shin EJ, Han J, Sohn JT, Kim JW, Kang D. 2019. Involvement of TREK-1 channel in cell viability of $\mathrm{H} 9 \mathrm{c} 2$ rat cardiomyoblasts affected by bupivacaine and lipid emulsion. Cells 8:454. 